\title{
Estudos complementares da infecção por Mannheimia granulomatis (lechiguana) em bovinos ${ }^{1}$
}

\author{
Daniela I.B. Pereira ${ }^{2}$, Franklin Riet-Correa ${ }^{2}$ e Silvia L. Ladeira ${ }^{2}$
}

\begin{abstract}
Pereira I.B., Riet-Correa F. \& Ladeira S.S. 2000. [Complementary studies of the infection by Mannheimia granulomatis (lechiguana) in cattle.] Estudos complementares da infecção por Mannheimia granulomatis (lechiguana) em bovinos. Pesquisa Veterinária Brasileira 20(3):91-96. Laboratório Regional de Diagnóstico, Faculdade de Veterinária, Universidade Federal de Pelotas, 96010-900 Pelotas, RS, Brazil.

Several experiments were performed to demonstrate the role of Dermatobia hominis in the etiology of lechiguana: (1) One calf was infected simultaneously with Dermatobia hominis larvae and Mannheimia granulomatis. Biopsies were performed in two larval lesions. An eosinophilic lymphangitis with connective tissue proliferation, similar to those observed in lechiguana, were present in one biopsy. (2) To detect if Dermatobia hominis is a carrier of Mannheimia granulomatis, a bacteriologic study was performed in 72 larvae and the same number of exudate samples from larval lesions. The bacterium was not isolated. (3) In 9 cattle spontaneously infected by Dermatobia hominis, the larval lesions were inoculated with Mannheimia granulomatis. One bovine whose larval lesions were contaminated with bacteria developed a lechiguana 3 months after inoculation. (4) Two fibroproliferative lesions, clinically similar to lechiguana, caused by Dermatobia hominis larvae were studied. Histologically, these lesions were characterized by proliferation of fibrous tissue with focal granulomas. Eosinophilic lymphangitis and calcification of collagenous fibers were not observed in the lesions. As Dermatobia hominis occasionally produces a fibrogranulomatous reaction, it is possible that this can be the initial lesion for lechiguana, if infected by Mannheimia granulomatis. (5 and 6) Two experiments were performed to detect if healthy cattle can carry Mannheimia granulomatis. The bacterium was not isolated from the tonsils of 153 cattle, and the immunodiffusion test to detect antibodies in cattle was not sufficiently sensitive to detect carrier cattle. (7) Seventeen new spontaneous cases of lechiguana are reported. All cases had the same clinical and pathologic characteristics as previously described. Fourteen cases were from southern Rio Grande do Sul, three were from the state of Santa Catarina and one from Paraná.
\end{abstract}

INDEX TERMS: Lechiguana, cattle, Dermatobia hominis, Mannheimia granulomatis

RESUMO.- Vários experimentos foram realizados para demonstrar a participação de Dermatobia hominis na etiologia da lechiguana: (1) Lesões experimentais causadas por larvas da mosca em um bovino foram infectadas com Mannheimia granulomatis. Foram realizadas biópsias em duas lesões produzidas pela larva. Em uma dessas biópsias foi observada

\footnotetext{
${ }^{1}$ Aceito para publicação em 29 de fevereiro de 2000.

Realizado com o apoio financeiro do Conselho Nacional de Desenvolvimento Científico e Tecnológico (CNPq).

${ }^{2}$ Laboratório Regional de Diagnóstico, Faculdade de Veterinária, Universidade Federal de Pelotas, 96010-900, Pelotas, RS.
}

linfangite eosinofílica e proliferação de tecido conectivo, similares às encontradas na lechiguana. (2) Com o objetivo de detectar a possível participação de Dermatobia hominis como vetor de Mannheimia granulomatis, foi realizado o estudo bacteriológico de 72 larvas e o mesmo número de exsudatos, provenientes de lesões de Dermatobia hominis, não tendo sido isolada a bactéria em nenhuma oportunidade. (3) Lesões espontâneas da mosca foram infectadas com uma suspensão da bactéria em 9 bovinos, sendo que um dos animais desenvolveu uma lesão de lechiguana 3 meses após a inoculação. (4) Foram estudadas duas lesões fibroproliferativas, clinicamente similares a lechiguana, causadas pela larva de 
Dermatobia hominis. Histologicamente estas lesões caracterizam-se por proliferação de tecido fibroso com presença de granulomas focais, diferenciando-se da lechiguana por não apresentar linfangite eosinofílica e calcificação de fibras colágenas. $\mathrm{O}$ fato de Dermatobia hominis, ocasionalmente, produzir uma reação fibrogranulomatosa, sugere que esta poderia ser a lesão inicial da lechiguana, se infectada por Mannheimia granulomatis. (5 e 6) Dois experimentos foram realizados para detectar se bovinos sadios podem ser portadores de Mannheimia granulomatis. A bactéria não foi isolada de amígdalas de 153 bovinos e a técnica de imunodifusão radial utilizada para a deteç̧ão de anticorpos não apresentou sensibilidade suficiente para identificar animais portadores. (7) Foram estudados 17 novos casos da doença, e em todos os casos, as características clínicas e patológicas foram similares às observadas em casos anteriores. Quatorze casos foram provenientes do sul do Rio Grande do Sul, três do Estado de Santa Catarina e um do Paraná.

TERMOS DE INDEXAÇÃO: Lechiguana, bovinos, Dermatobia hominis, Mannheimia granulomatis.

\section{INTRODUÇÃO}

A lechiguana é uma enfermidade dos bovinos caracterizada pelo aparecimento de uma tumoração que cresce rapidamente e normalmente é acompanhada de emagrecimento progressivo, podendo levar à morte do animal em 3 a 12 meses, se não tratado. Tem sido observada freqüentemente na região sul do Rio Grande do Sul (Riet-Correa et al. 1992, Ladeira et al. 1996), porém foi diagnosticada, também, em Minas Gerais (Varaschin \& Silva 1998) e São Paulo (Birgel et al. 1999). A lesão é arredondada, muito consistente, geralmente localizada na região escapular e áreas adjacentes. Os linfonodos regionais estão aumentados de tamanho. Macroscopicamente o tumor caracteriza-se por tecido fibroso, consistente e esbranquiçado com pontos amarelados. Ao exame histológico caracteriza-se por uma paniculite fibrogranulomatosa, com marcada proliferação de tecido fibroso, infiltrado por plasmócitos eosinófilos, linfócitos e, ocasionalmente, neutrófilos. Vasos linfáticos dilatados contendo numerosos eosinófilos são observados dentro do tecido fibroso. Depósitos de material eosinofílico, originado, provavelmente, da degranulação e marginação de eosinófilos ocorrem próximos à parede dos linfáticos inflamados. Microabscessos eosinofilicos, formados principalmente por eosinófilos e algumas células mononucleares indiferenciadas são observados, também, dentro do tecido fibroso. Esses microabscessos formamse, aparentemente, após a ruptura dos vasos linfáticos inflamados. Estruturas similares a rosetas, com material eosinofilico ou basofilico no centro e projeções periféricas PAS positivas (material de Splendore-Hoeppli) ocorrem, ocasionalmente, dentro dos linfáticos inflamados ou nos microabscessos. Colônias de bactérias Gram negativas são observadas no centro dessas rosetas. Na maioria das lesões, numerosas fibras colágenas estão calcificadas. Em consequiência da invasão dos músculos adjacentes, muitas fibras musculares degeneradas observam-se entre as fibras colágenas. Células musculares multinucleadas, causadas por regeneração por brotação, estão, também, presentes. Os gânglios linfáticos regionais apresentam proliferação de tecido fibroso da cápsula e trabéculas e linfangite eosinofílica dos vasos linfáticos aferentes. Granulomas eosinofílicos, rodeados por células epitelioídes e tecido fibroso, e contendo rosetas no seu interior, são observados dentro dos gânglios. (Riet-Correa et al. 1992).

Através da cultura de material obtido de biópsias profundas das lesões, foi isolada uma bactéria classificada como Pasteurella granulomatis (Ribeiro et al. 1989), posteriormente designada como Mannheimia granulomatis (Angen et al. 1999). A participação desta bactéria como agente etiológico da lechiguana é evidenciada pelos seguinte fatos: isolamento constante de Mannheimia granulomatis de biópsias profundas das lesões; recuperação dos bovinos afetados após tratamento com cloranfenicol, ao qual todas as cepas foram sensíveis; lesões histológicas características de uma infecção bacteriana, evidenciadas pela presença de bactérias, cocobacilos gram negativos, no centro dos linfáticos inflamados e microabscessos; e a reprodução experimental, em 2 animais, de uma lesão similar às observadas nos casos espontâneos de lechiguana (Riet-Correa et al. 1992, Ladeira et al. 1996).

A enfermidade foi reproduzida experimentalmente por Ladeira et al. (1996) ao inocularem a bactéria em lesões espontâneas de Dermatobia hominis. Este fato sugere que o parasitismo por Dermatobia hominis esteja relacionado, de alguma forma, com a ocorrência de lechiguana. A participação de Dermatobia hominis na transmissão de Mannheimia granulomatis e/ou desenvolvimento da lesão é indicado, também, pelos seguintes fatos: as lesões causadas pelas duas doenças localizam-se na região escapular e suas proximidades; as duas enfermidades têm a mesma distribuição geográfica na região sul do Rio Grande do Sul; e a diminuição da frequiência dos casos de lechiguana quando iniciou-se o controle da parasitose mediante o uso de carrapaticidas piretróides (Ladeira et al. 1996).

Os objetivos deste trabalho foram: (1) determinar a participação da Dermatobia hominis e Mannheimia granulomatis na patogenia da lechiguana; (2) caracterizar sorologicamente isolados de Mannheimia granulomatis; (3) detectar anticorpos em bovinos infectados experimental ou espontâneamente com Mannheimia granulomatis; (4) detectar anticorpos contra Mannheimia granulomatis em bovinos com e sem parasitismo por Dermatobia hominis; (5) investigar a presença de Mannheimia (Pasteurella) granulomatis e outras espécies de Pasteurella em amígdalas de bovinos; (6) realizar o estudo de novos casos de lechiguana.

\section{MATERIAL E MÉTODOS}

Para estudar a participação da Dermatobia hominis na patogenia da lechiguana foram realizados 4 experimentos diferentes. No Experimento 1, 304 larvas de Dermatobia hominis colhidas de bovinos com infestação natural foram cultivadas no laboratório. As 71 larvas obtidas foram inoculadas em um bovino, em 4 locais, 2 de cada lado da região pré-escapular (Ribeiro \& Oliveira 1983). Antes da infestação e, semanalmente, durante as 4 semanas seguintes, as regiões foram pinceladas com suspensão de Mannheimia granulomatis (cepa 145/ 91), preparada segundo Ladeira et al. (1996). 
No Experimento 2 realizou-se o estudo bacteriológico de larvas de Dermatobia hominis e de exsudatos provenientes dessas lesões em bovinos infestados naturalmente, pertencentes a propriedades com e sem história de lechiguana. A hemolinfa de 72 larvas coletadas foi retirada com o auxílio de seringa e agulha estéril e semeada em placas de petri com agar sangue ovino a $5 \%$. Igual número de exsudatos foram coletados com zaragatoa e igualmente semeados.

No Experimento 3, lesões espontâneas de Dermatobia hominis, em 9 bovinos, foram inoculadas com suspensão de Mannheimia granulomatis. Antes da inoculação e 7 dias após, foram coletadas, respectivamente, 5 larvas e o mesmo número de exsudatos e semeados conforme experimento anterior para avaliação bacteriológica.

O experimento 4 foi realizado com o objetivo de estudar a patologia de lesões de Dermatobia hominis e relacioná-la com as lesões de lechiguana. Para isto, foram coletadas lesões de 3 bovinos abatidos em frigoríficos da região. Outros dois materiais foram provenientes de bovinos que apresentavam lesões similares a lechiguana. Todas as amostras foram fixadas em formol a $10 \%$, incluídas em parafina, cortadas a $6 \mathrm{~m} \mu$ e coradas por hematoxilina-eosina (HE).

No Experimento 5 foi realizada a caracterização sorológica de diferentes isolados de Mannheimia granulomatis e a deteç̧ão de anticorpos em bovinos utilizando-se a técnica de imunodifusão radial. Para a realização de imunodifusão radial foram utilizados 8 isolados de Mannheimia granulomatis como antígeno, preparado conforme Schramm (1991). Os soros hiperimunes foram preparados em coelhos seguindo a técnica descrita por Carter (1972) e testados com antígenos homólogos e heterólogos. Foram testados 117 soros

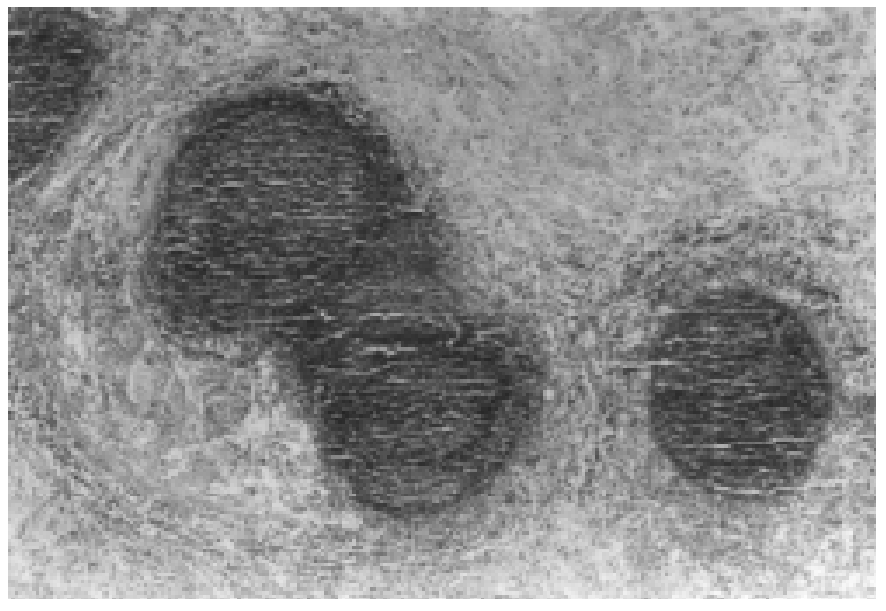

1

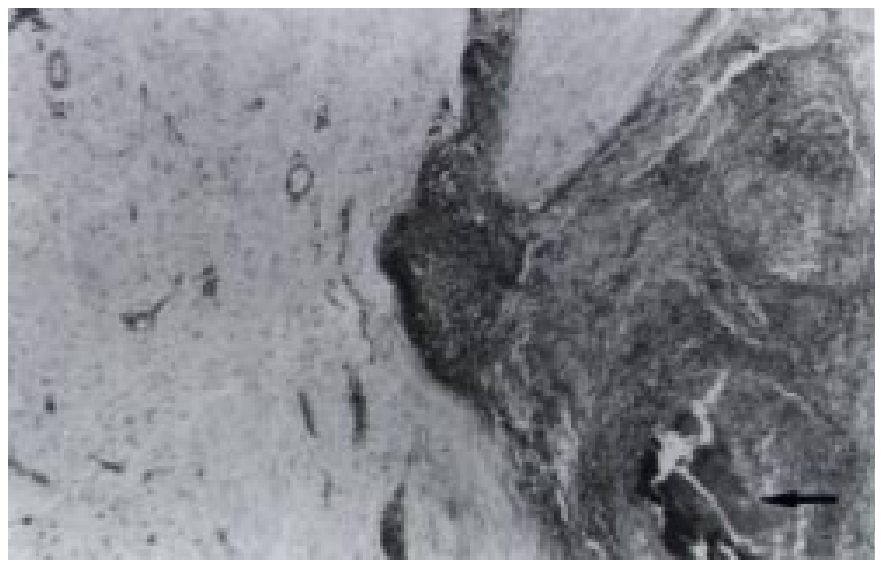

bovinos, sendo 74 provenientes de propriedades com infestação por Dermatobia hominis; 37 de propriedades sem infestação; 5 de bovinos com lechiguana; 1 de um bovino que havia tido a doença aproximadamente 4 anos antes da coleta de sangue e 2 soros de bovinos que haviam sido inoculados com suspensão de Mannheimia granulomatis, um por via subcutânea e outro por pincelamento em lesões de Dermatobia hominis.

No Experimento 6 foram coletadas amígdalas de 153 bovinos abatidos em frigoríficos da região. As amígdalas eram flambadas em sua superfície e, após a incisão com bisturi, coletava-se com zaragatoa o material a ser semeado em agar sangue ovino e agar MacConkey. As placas eram incubadas a $37^{\circ} \mathrm{C}$ por 24 horas. A caracterização bacteriana foi realizada através do método de Gram e provas bioquímicas.

No Experimento 7 foi realizado o estudo de 17 casos espontâneos de lechiguana no período de 1992-1996. Em 15 casos realizaram-se biópsias profundas das lesões e o material foi utilizado para isolamento bacteriológico. De todos os casos foi realizado o estudo histopatológico. Nove animais foram tratados com $3 \mathrm{~g}$ de cloranfenicol por 5 dias consecutivos e 3 bovinos foram tratados com $3 g$ de ceftiofur sódico, pelo mesmo tempo.

\section{RESULTADOS}

No animal inoculado no Experimento 1, em dois locais de inoculação, houve o desenvolvimento de um nódulo de aproximadamente $5 \mathrm{~cm}$ de diâmetro. No estudo histológico da biópsia realizada no $14^{\circ}$ dia observou-se a presença de

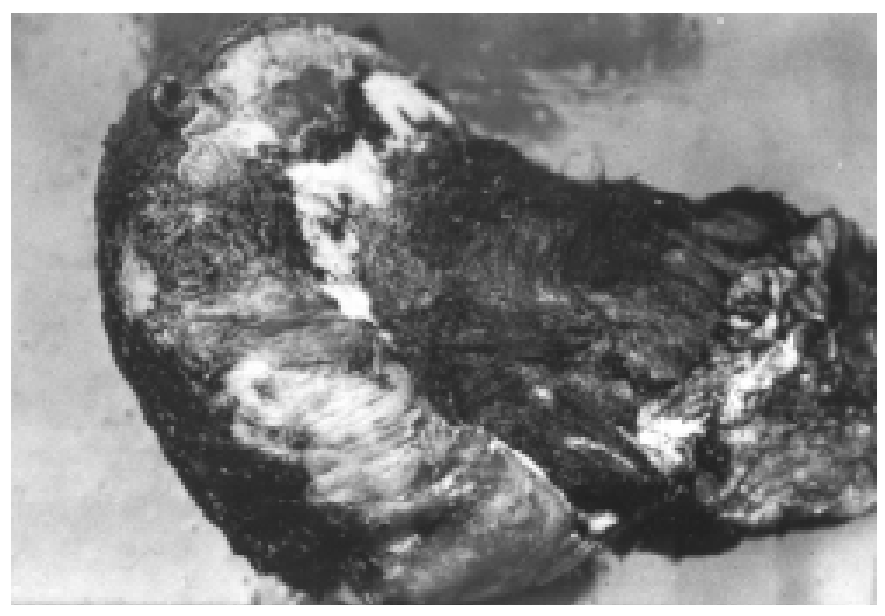

Fig. 1. Tecido subcutâneo de bovino inoculado simultaneamente com larvas de Dermatobia hominis e Mannheimia granulomatis. Biópsia realizada no $14^{\circ}$ dia após a inoculação. Observam-se linfangite eosinofílica caraterizada por vasos linfáticos dilatados contendo numerosos eosinófilos e proliferação de tecido conectivo jovem com infiltrado de células mononucleares e eosinófilos. HE, obj. 4.

Fig. 2. Lesão proliferativa causada espontaneamente por Dermatobia hominis. A massa, que estava ulcerada, foi extraída cirurgicamente da região escapular.

Fig. 3. Lesão proliferativa causada por Dermatobia hominis. Observase um granuloma contendo restos de larvas (seta) rodeado por tecido conectivo denso. Se diferencia da lesão de lechiguana pela ausência de linfangite eosinofílica, nem presença de rosetas com material de Splendore-Hoeppli e nem calcificação de fibras colágenas. HE, obj. 4. 


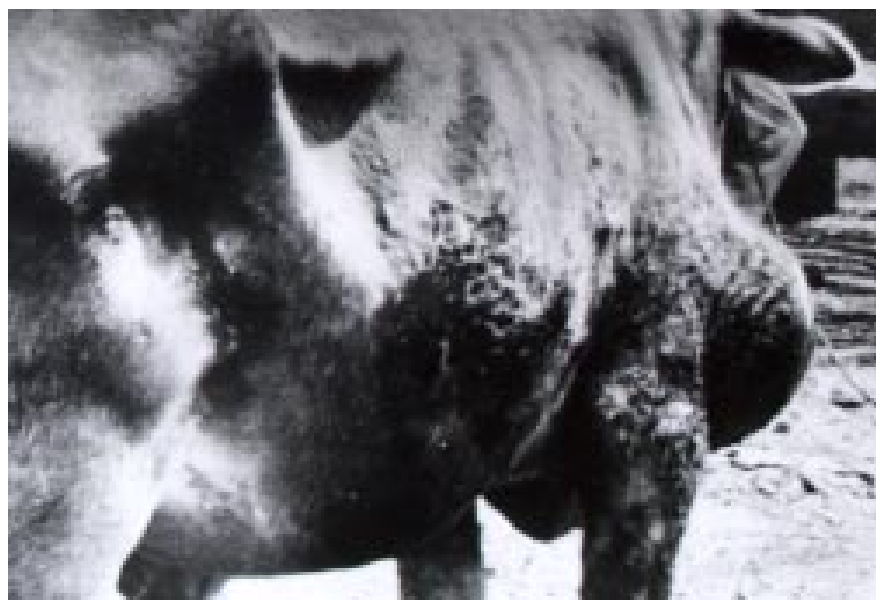

Fig. 4. Lesão de lechiguana localizada na região escapular direita de bovino.

microabscessos e linfangite eosinofilica contendo rosetas com reação tipo Splendore-Hoeppli e intensa proliferação de tecido conjuntivo com células inflamatórias mononucleares e eosinófilos (Fig. 1). Na histologia da biópsia realizada no $28^{0}$ dia observou-se acúmulo de numerosos neutrófilos e eosinófilos necróticos ao redor da larva e presença de dermatite perivascular eosinofilica.

Os resultados do estudo bacteriológico de larvas e exsudatos das lesões causadas pela Dermatobia hominis (Experimento 2) apresentam-se no Quadro 1.

No estudo bacteriológico de larvas e lesões após a inoculação com suspensão de Mannheimia granulomatis (Experimento 3), foi isolada Mannheimia granulomatis da hemolinfa de uma larva 7 dias após a inoculação, enquanto que das larvas e exsudatos coletados antes da inoculação não foi isolada a bactéria. Um dos bovinos utilizados para a inoculação com a bactéria, 3 meses após, desenvolveu um tumor com características clínicas da lechiguana. $O$ tumor estava localizado na região dorsal, a altura das escápulas, e media $23 \mathrm{~cm}$ longitudinal, $19 \mathrm{~cm}$ transversal e $5 \mathrm{~cm}$ de altura. Mannheimia granulomatis foi isolada em cultivo puro a partir da biópsia realizada. Na histologia observou-se proliferação focal de tecido fibroso constituído principalmente por fibras colágenas, estando algumas destas calcificadas. Entre o tecido fibroso observaram-se plasmócitos, eosinófilos, linfócitos e, em menor quantidade, neutrófilos. Verificaram-se linfangite eosinofílica evidenciada pela dilatação dos vasos linfáticos e presença de microabscessos formados principalmente por eosinófilos. No centro de alguns microabscessos observou-se a presença de estruturas eosinofílicas semelhantes a rosetas. $\mathrm{O}$ bovino foi tratado com $3 \mathrm{~g}$ de cloranfenicol durante 5 dias, havendo a regressão total da lesão em 15 dias.

No estudo patológico de lesões espontâneas causadas por Dermatobia hominis (Experimento 4), observou-se a presença de nódulos na pele com exsudato seroso, sero-hemorrágico ou purulento. Os nódulos apareciam isolados ou em grupos, estes últimos contendo de 50 a 100 larvas em áreas de 10 a $20 \mathrm{~cm}$ de diâmetro, localizados nas regiões escapular, dorsal,

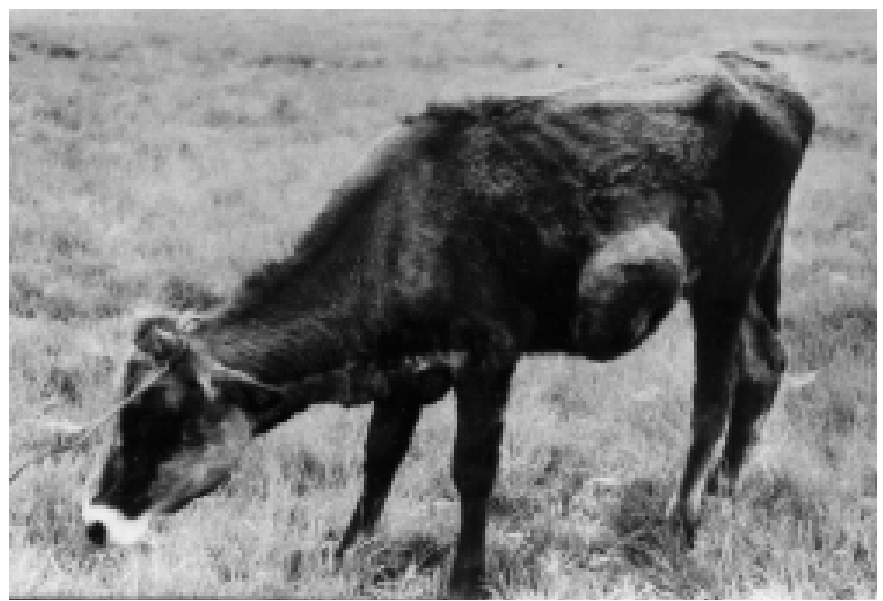

Fig. 5. Lesão de lechiguana localizada na região abdominal esquerda de bovino.

lateral das costelas e pescoço. Histologicamente observaramse numerosos neutrófilos e eosinófilos necróticos ao redor das larvas e dermatite, preferentemente perivascular, com infiltrado de células mononucleares e eosinófilos. Outro tipo de lesão foi encontrado em 2 animais; macroscopicamente era muito similar a lechiguana (Fig. 2), com crescimento rápido e consistência firme, localizada na região escapular. Ao corte a superfície da lesão demonstrou consistência firme e coloração esbranquiçada e, em algumas áreas, haviam larvas pequenas de Dermatobia hominis isoladas ou em grupos, que pareciam ter seu desenvolvimento inibido. A lesão caracterizou-se, histologicamente, por severa proliferação de tecido fibroso com granulomas focais distribuídos dentro do mesmo (Fig. 3). No centro desses granulomas observou-se a presença de larvas ou restos das mesmas envolvidas por uma intensa reação inflamatória constituída por neutrófilos, mastócitos, células mononucleares, macrófagos e alguns eosinófilos. Mannheimia granulomatis não foi isolada dessas lesões.

No teste de imunodifusão radial, no Experimento 5, todos os antígenos testados reagiram com os soros hiperimunes homólogos e heterólogos. Dos soros bovinos testados apenas um soro proveniente de propriedade com infestação por Dermatobia hominis e os soros dos bovinos com a doença rea-

Quadro 1. Estudo bacteriológico da hemolinfa de larvas de Dermatobia hominis e exsudatos de lesões

\begin{tabular}{lcc}
\hline \multicolumn{1}{c}{ Agente isolado } & Hemolinfa & Exsudato \\
\hline Stapylococccus aureus & 27 & 31 \\
Stapylococccus spp & 19 & 16 \\
Corynebacterium spp & 10 & 8 \\
Actinomyces pyogenes & 2 & 2 \\
Streptococcus spp & 2 & 3 \\
Shigella spp & 1 & 0 \\
Corynebacterium haemolyticum & 0 & 1 \\
Poliflora microbiana & 8 & 8 \\
Sem caracterização do agente & 3 & 4 \\
Sem isolamento bacteriano & 3 & 3
\end{tabular}



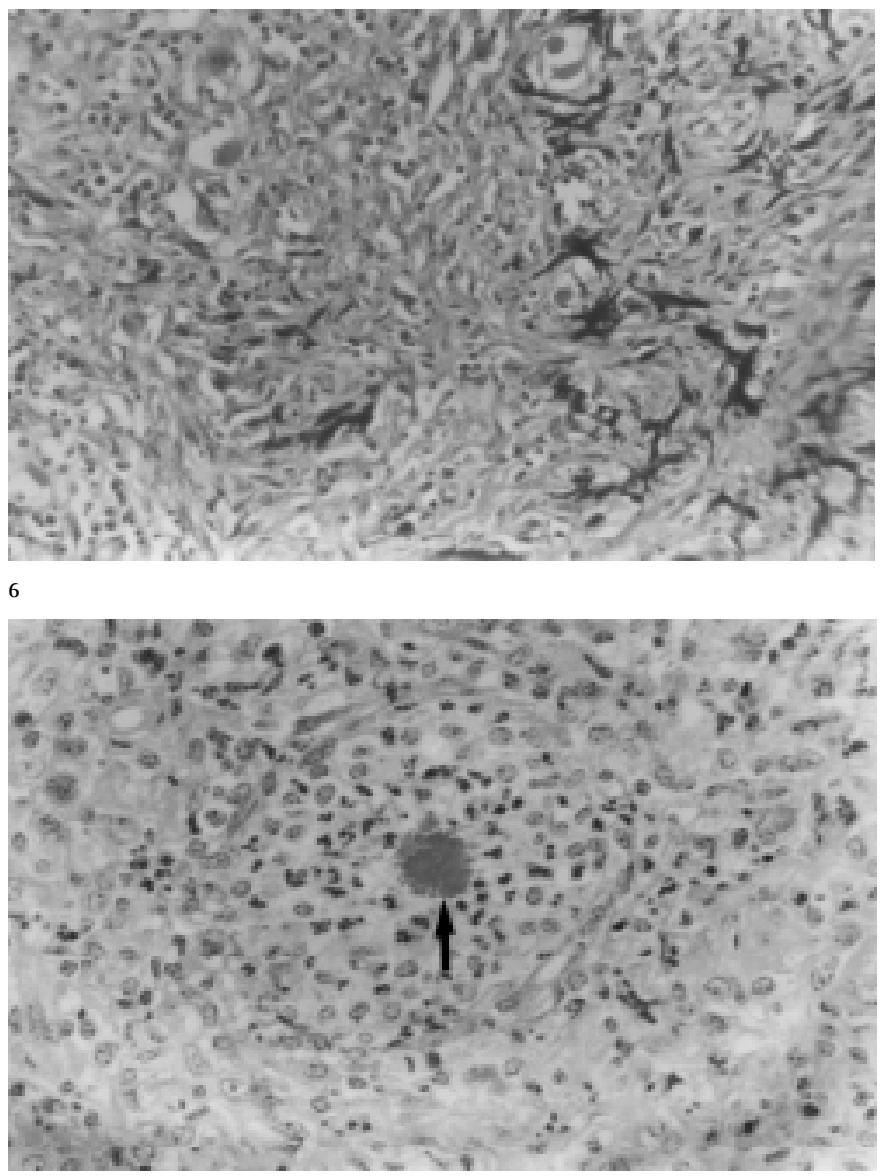

giram. Nos soros dos bovinos inoculados com suspensão bacteriana, foram detectados anticorpos no animal inoculado por via subcutânea até o $18^{\circ}$ dia após a inoculação.

No Experimento 6, das 153 amígdalas de bovinos coletadas, foram isolados 39 isolamentos, 31 foram classificados como Pasteurella multocida, 7 como Pasteurella sp e 1 como Pasteurella haemolytica. Mannheimia granulomatis não foi isolada.

Dos 17 novos casos de lechiguana estudados no Experimento 7, 14 foram provenientes do Rio grande do Sul; 4 foram observados no município de Canguçu, 5 em Morro Redondo, 3 em Pelotas e um no município de Cachoeira do Sul. Três casos foram observados no Estado de Santa Catarina pelo Dr. Ademir Mondadori e um no Estado do Paraná pelo Dr. Evaldo da Silva. Todos os casos ocorreram em áreas onde é frequiente o parasitismo por Dermatobia hominis. A doença foi constatada em diversas raças de bovinos e foram afetados animais de $1 \mathrm{a} 15$ anos de idade e em todas as épocas do ano. Em $15(83,3 \%)$ dos casos a lesão estava localizada na região escapular e suas proximidades (Fig. 4). Em três casos (16,5\%) a lesão estava localizada em outras regiões como a região glútea, região lateral esquerda do abdômen (Fig. 5) e região lombar. Em 5 animais $(27,7 \%)$ foi observada a presença de lesões de Dermatobia hominis nas regiões adjacentes à lesão. No estudo histológico todos os casos apresentaram lesões

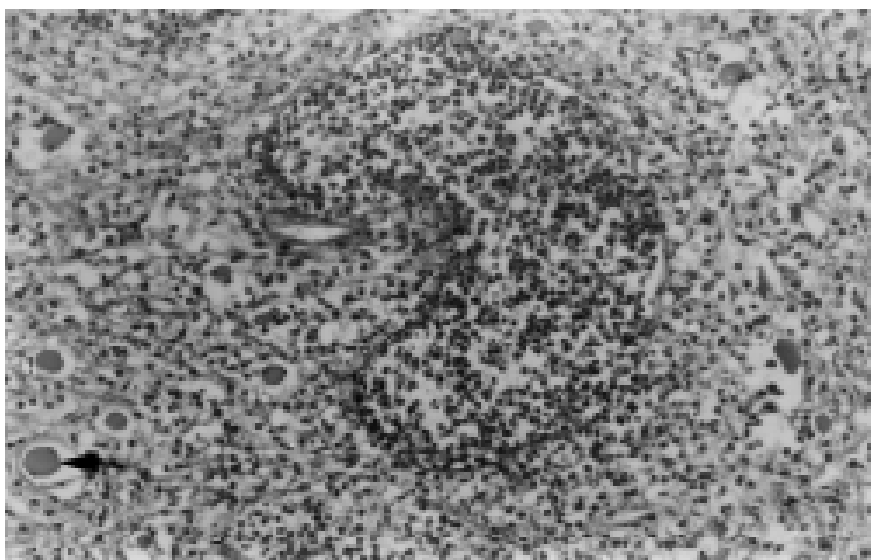

Fig. 6. Lesão espontânea de lechiguana. Tecido conectivo denso com calcificação de fibras colágenas. HE, obj. 10.

Fig. 7. Lesão espontânea de lechiguana. Vaso linfático dilatado contendo eosinófilos. O estroma de tecido conectivo está infiltrado por eosinófilos e células mononucleares. Observamse fibras musculares (seta) entre o tecido conectivo. HE, obj. 10.

Fig. 8. Lesão espontânea de lechiguana. Vaso linfático dilatado contendo eosinófilos e com presença de uma roseta central (seta) contendo material de Splendore-Hoeppli. HE, obj. 20.

características da enfermidade, com severa proliferação de tecido fibroso com calcificação de fibras colágenas (Fig. 6). Linfáticos dilatados, com presença de numerosos eosinófilos, (Fig 7) e microabscessos eosinofilicos eram observados entre o tecido fibroso. Rosetas com presença de material de Splendore-Hoeppli eram, ocasionalmente, encontradas dentro desses linfáticos dilatados ou nos microabscessos (Fig 8). Numerosos eosinófilos, linfócitos e plasmócitos, assim como fibras musculares degeneradas, observavam-se no estroma do tecido conectivo (Fig. 7). Os 9 bovinos tratados com cloranfenicol demonstraram regressão total da lesão entre 15 e 21 dias após o tratamento, enquanto que os 3 bovinos tratados com ceftiofur sódico apresentaram regressão mais lenta da lesão.

\section{DISCUSSÃO}

Na tentativa de comprovar a hipótese de que o parasitismo por Dermatobia hominis participa na patogenia da lechiguana foram estudadas lesões causadas por infecções mistas de Dermatobia hominis e Mannheimia granulomatis (Experimento 1), reproduzindo-se uma lesão histologicamente similar às lesões observadas na lechiguana, o que fortalece a hipótese postulada por Ladeira et al. (1996), de que esta doença é causada por uma associação entre Mannheimia granulomatis e Dermatobia hominis. Em um trabalho anterior sugere-se a pos- 
sibilidade de que a Dermatobia hominis seja o vetor de Mannheimia granulomatis (Ladeira et al. 1996). Este fato não foi comprovado no estudo bacteriológico de larvas e lesões de Dermatobia hominis (Experimento 2), no qual a bactéria não foi isolada em nenhuma das 72 larvas e exsudatos de lesões causadas pelas mesmas. No Experimento 3, o desenvolvimento de uma lechiguana em um dos bovinos inoculados com suspensão de Mannheimia granulomatis em lesões espontâneas de Dermatobia hominis, parece indicar que a mesma ocorreu em consequiência da inoculação das lesões com a bactéria. Esta observação e os resultados obtidos por Ladeira et al. (1996) parecem confirmar que a doença é produzida em algumas ocasiões em que a bactéria está presente em lesões causadas pela mosca. À semelhança do observado por Ladeira et al. (1996) a lechiguana ocorreu após a formação do terceiro ínstar de Dermatobia hominis e posterior saída desta da lesão. No Experimento 4, o estudo de lesões histológicas causadas por Dermatobia hominis foram similares àquelas descritas por Sanavria et al. (1987). No entanto, foram encontrados dois bovinos com lesões fibroprolife-rativas. Estas lesões não são descritas na literatura e histologicamente são similares à lesão de lechiguana por apresentar uma severa proliferação de tecido fibroso. Entretanto, difere da lesão observada na lechiguana, por não apresentar linfagite eosinofilica, nem presença de rosetas com material de Splendore-Hoeppli e nem calcificação de fibras colágenas. A similaridade das lesões fibrogranulomatosa produzidas por Dermatobia hominis com as lesões de lechiguana, parecem indicar que a larva, aparentemente quando fica inibido o seu desenvolvimento no tecido subcutâneo, causa uma lesão fibroproliferativa que poderia ser a lesão inicial da lechiguana se for infectada por Mannheimia granulomatis. Este fato fortalece a hipótese de que a larva de Dermatobia hominis participa junto a Mannheimia granulomatis na etiologia da lechiguana, e como na lechiguana, as lesões fibroproliferativas ocorrem com pouca frequiência.

A possibilidade de que bovinos sejam portadores de Mannheimia granulomatis foi estudada através da detecção de Pasteurella spp em amígdalas de 153 bovinos sadios e através da detecção de anticorpos pelo teste de imunodifusão radial (Experimentos 5 e 6). 0 isolamento de diversas espécies de Pasteurella confirma que algumas espécies deste gênero bacteriano são freqüentemente encontradas na nasofaringe de bovinos sadios (Carter 1981). Isto parece não ocorrer com Mannheimia granulomatis já que a bactéria não foi isolada das amígdalas estudadas. Na imunodifusão radial, o fato de que somente foram detectados anticorpos em bovinos com doença clínica, ou por um período de 18 dias após inoculação subcutânea com suspensão bacteriana em um animal, indica que a prova não apresenta sensibilidade suficiente para detectar animais portadores. Por outro lado, a adsorção dos soros hiperimunes demonstrou que as cepas isoladas não apresentam diferenças antigênicas entre si. Essa constatação é similar à observada por Veit et al. (1996) que comprovaram não haver diferença antigênica significativa entre 13 cepas de Mannheimia granulomatis estudadas através da técnica de Reação de Polimerase em Cadeia (PCR).
Os 17 novos casos de lechiguana estudados entre os anos de 1992 e 1996 no Experimento 7 apresentaram características clínicas e patológicas similares às observadas em casos anteriores e Mannheimia granulomatis foi isolada das lesões. Um fato a ser destacado é a distribuição geográfica da enfermidade, já que em estudos anteriores a mesma só tinha sido diagnosticada em uma área de aproximadamente 500.000 hectares próxima a região de Pelotas. Nos casos estudados neste trabalho a doença também foi observada no município de Cachoeira do Sul, localizado em outra região do Rio Grande do Sul e nos Estados de Santa Catarina e Paraná. Recentemente a enfermidade foi diagnosticada, também, nos Estados de Minas Gerais (Varaschin \& Silva, 1998) e São Paulo (Birgel et al. 1999), o que comprova que a lechiguana ocorre em outras regiões do Brasil, e sugere a possibilidade de que ocorra em outros países onde os bovinos são parasitados por Dermatobia hominis.

\section{REFERÊNCIAS}

Angen O., Mutters R., Caugant D.A., Olsen, J.E. \& Bisgaard M. 1999. Taxonomic relationships of the (Pasteurella) haemolytica complex as evaluated by DNADNA hybridizations and $16 \mathrm{~S}$ rRNA sequencing with proposal of Mannheimia haemolytica gen. nov., comb. nov., Mannheimia granulomatis comb. nov., Mannheimia glucosida sp. nov., Mannheimia ruminalis sp. nov. and Mannheimia varigena sp. nov. Int. J. Syst. Bacteriol. 1: 67-86.

Birgel Jr. E.H., Ollhoff R.D., Benesi F.J., Viana R.B., Schalch U.M., Pacheco J.C.G., Florio W.A.B., Ramos M.C.C. \& Birgel E.H. 1999. Ocorrência de Lechiguana (paniculite fibrogranulomatosa proliferativa) em bovino criado no Estado de São Paulo. Arq. Inst. Biol., São Paulo, 66 (supl.): 130.

Carter G.R. 1972. Simplified identification of somatic varieties of Pasteurella multocida causing fowl cholera. Avian Dis. 16: 1109-1114.

Carter G.R. 1981. The Genus Pasteurella, p. 1383-1391. In: Starr P.M., Stolp H., Trüper G. H., Balows A. \& Schlegel G. H. (eds) The Prokaryotes. A Handbook on Habitats, Isolation, and Identification of Bacteria. Springer Verlag, New York.

Ladeira S.L., Riet-Correa F., Pereira D.B. \& Carter, G.R. 1996. Role of Pasteurella granulomatis and Dermatobia hominis in the etiology of lechiguana in cattle. Ann. N. Y. Acad. Sci. 791: 359-368.

Ribeiro G.A., Carter G.R., Frederiksen W. \& Riet-Correa F. 1989. Pasteurella haemolytica-like bacterium from a progressive granuloma of cattle in Brazil. J. Clin. Microbiol. 27(6): 1401-1402.

Ribeiro P.B. \& Oliveira C.M.B. 1983. Fase parasitária da Dermatobia hominis sobre bovinos. Arq. Bras. Med. Vet. Zootec. 35(5): 691-698.

Riet-Correa F., Méndez M.C., Schild A.L., Ribeiro G.A. \& Almeida S.M. 1992. Bovine focal proliferative fibrogranulomatous panniculitis (lechiguana) associated with Pasteurella granulomatis. Vet. Pathol. 29: 93-103.

Sanavria A., Lopez C.W.G. \& Moya Borja G.E. 1987. Histopatologia da pele de bovino na infecção experimental por Dermatobia hominis. Arq. Univ. Fed. Rur. Rio de Janeiro 10 (1-2): 9-23.

Schramm R.C. 1991. Estudo da população da Moraxella bovis no globo ocular de um bovino. Tese de Mestrado, Faculdade de Veterinária da Universidade Federal de Pelotas, Pelotas, p.39.

Varaschin M. S. \& Silva A. M. 1998. Paniculite fibrogranulomatosa focal em bovino de Minas Gerais. Ciência Rural, Sta Maria, 28: 151-153.

Veit H.P., Carter G.R., Riet-Correa F. \& Brown S.S. 1996. The use of polymerase chain reaction to identify Pasteurella granulomatis from cattle. Ann. N. Y. Acad. Sci. 791: 350-358. 